\title{
Acute Myeloid Leukemia Developing with Acute Pancreatitis Mimicking Autoimmune Pancreatitis
}

\author{
Ryohei Sumitani ${ }^{1}$, Taiki Hori ${ }^{1}$, Jumpei Murai ${ }^{1}$, Shiyori Kawata ${ }^{1}$, Masahiro Oura ${ }^{1}$, \\ Kimiko Sogabe ${ }^{1}$, Mamiko Takahashi ${ }^{1}$, Takeshi Harada ${ }^{1}$, Shiro Fujii ${ }^{1}$, Hirokazu Miki ${ }^{2}$, \\ Kumiko Kagawa ${ }^{1}$, Masahiro Abe ${ }^{1}$ and Shingen Nakamura ${ }^{1}$
}

\begin{abstract}
:
A 33-year-old man was admitted to our hospital for fever and abdominal pain. A blood analysis revealed pancytopenia and increased serum pancreatic enzymes with disseminated intravascular coagulation. A detailed examination revealed acute pancreatitis, with diffuse swelling of the pancreas and diffuse beaded dilatation of the main pancreatic duct, which mimicked autoimmune pancreatitis complicated by acute myeloid leukemia. Systemic cytotoxic chemotherapy led to the remission of leukemia and pancreatitis. We hypothesized that the etiology of acute pancreatitis was invasion of leukemia cells. Acute pancreatitis is rare as a symptom of leukemia; however, we should consider the possibility of leukemia during the differential diagnosis of acute pancreatitis.
\end{abstract}

Key words: acute pancreatitis, autoimmune pancreatitis, acute myeloid leukemia

(Intern Med 60: 1753-1757, 2021)

(DOI: 10.2169/internalmedicine.4916-20)

\section{Introduction}

In general, acute leukemia develops with symptoms accompanying pancytopenia, such as anemia, bleeding tendency and febrile neutropenia (1). It is therefore possible to miss leukemia if other organ symptoms are dominant. We report a case of acute myeloid leukemia (AML) accompanied by abdominal pain due to acute pancreatitis.

\section{Case Report}

A 33-year-old man with a 5-year history of back pain due to lumbar disc herniation underwent microscopic herniotomy in April 2016. At one week after the surgery, he developed persistent fever and hypochondralgia. Abdominal computed tomography (CT) demonstrated swelling of the pancreatic head and dilatation of the main pancreatic duct. He was transferred to our hospital with acute pancreatitis. On physical examination, he had epigastric tenderness without the
Blumberg sign, left cervical lymphadenopathy, bilateral pretibial petechiae and splenomegaly with a two-finger breadth. Blood tests demonstrated pancytopenia with a hemoglobin level of $11.4 \mathrm{~g} / \mathrm{dL}$, a white blood cell count of $3,000 / \mu \mathrm{L}$ (blasts $12.5 \%$, mono $28.5 \%$ ) and a platelet count of $6.3 \times 10^{4} / \mu \mathrm{L}$. Hemostatic tests revealed an elongated prothrombin time of 14.7 seconds and an activated partial thromboplastin time of 40.5 seconds, with a D-dimer level of $3.0 \mu \mathrm{g} / \mathrm{mL}$. Blood chemistry and immunological analyses revealed the following findings: amylase, 802 IU/L; pancreatic amylase, $762 \mathrm{IU} / \mathrm{L}$; elastase 1, 5,587 IU/L; total bilirubin, $0.4 \mathrm{mg} / \mathrm{dL}$; LDH, $245 \mathrm{IU} / \mathrm{L}$; corrected calcium, $9.1 \mathrm{mg} /$ $\mathrm{dL}$; CRP, $4.8 \mathrm{mg} / \mathrm{dL}$; IgG, 1,528 mg/dL and IgG4, $72.8 \mathrm{mg} /$ $\mathrm{dL}$. The patient was negative for autoantibodies. A bone marrow examination revealed increased monoblasts $(38.6 \%)$ and eosinophils (8.1\%), with 270,000 copies/ $\mu$ gRNA of the CBF $\beta / M Y H 11$ fusion gene. On flow cytometry, monoblastic cells were positive for CD 13, 33, 34, and HLA-DR and negative for $\mathrm{CD} 2,3,4,5,7,8,10,19,20,16,56,14$, and 41. A chromosomal analysis demonstrated 46,XY,inv(16)(p

${ }^{1}$ Department of Hematology, Endocrinology and Metabolism, Institute of Biomedical Sciences, Tokushima University Graduate School, Japan and ${ }^{2}$ Division of Transfusion Medicine and Cell Therapy, Tokushima University Hospital, Japan

Received: March 23, 2020; Accepted: November 23, 2020; Advance Publication by J-STAGE: January 15, 2021

Correspondence to Dr. Shingen Nakamura, shingen@tokushima-u.ac.jp 
A
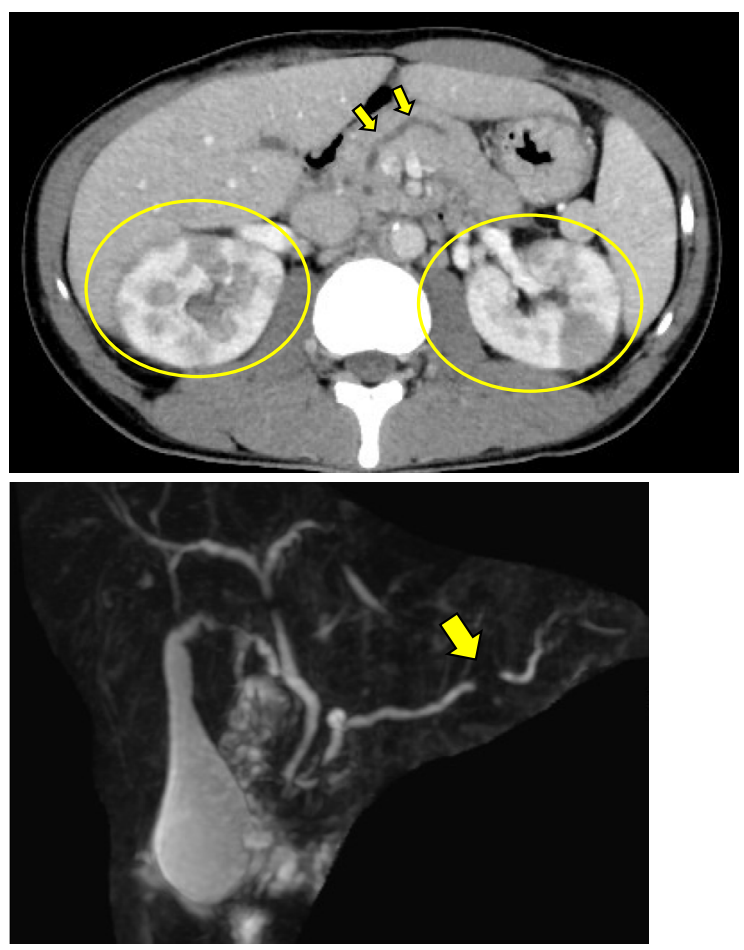

C

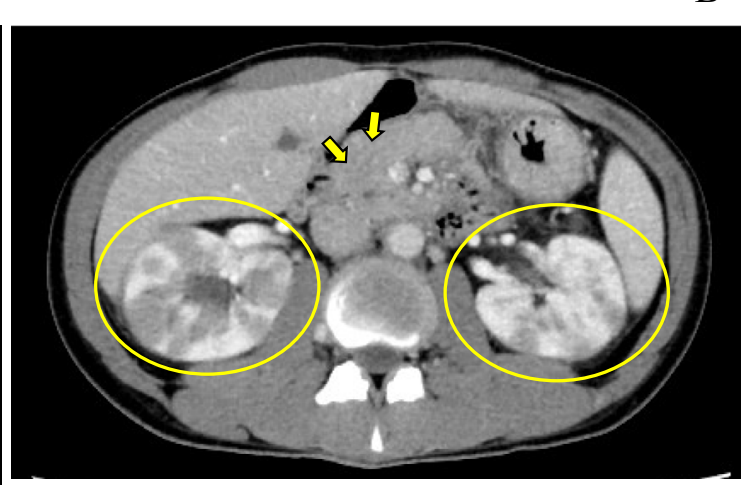

B

Figure 1. A, B: Computed tomography image of the abdomen on admission. Diffuse swelling of the pancreas, dilatation of the main pancreatic duct (arrows) and multiple enhancement defects in the bilateral kidneys (circles) were observed. C: Magnetic resonance cholangiopancreatography on admission showed beaded dilatation of the pancreatic duct and disruption of the main pancreatic duct (arrow).

13.1q22)[13]/47,idem,+22[5]. C-kit mutation was not investigated. Enhanced CT confirmed the dilatation of the main pancreatic duct, swelling of the pancreatic head, multiple cuneiform defects of the bilateral kidney and splenomegaly. Magnetic resonance cholangiopancreatography (MRCP) revealed disruption and dilation of the main pancreatic duct, which had a beaded appearance, without pancreatobiliary maljunction or biliary stones. We diagnosed the patient with AML with inv(16)(p13.1q22), and suspected invasion of leukemia cells to the kidneys and pancreas. Induction chemotherapy with idarubicin and cytarabine achieved hematological remission (Fig. 2). During consolidation therapy, MRCP and CT confirmed the disappearance of dilatation of the main pancreatic duct, swelling of the pancreas and multiple kidney defects. Disruption of the main pancreatic duct remained. No pancreatic pseudocyst developed in the healed pancreas after the treatment of pancreatitis. After eight months and three courses of high-dose cytarabine, the patient developed molecular relapse. Pancreatitis did not develop to the point of molecular relapse before hematological relapse. We performed re-induction therapy followed by unrelated bone marrow transplantation with a conditioning regimen consisting of fludarabine, busulfan and melphalan. The disruption of the main pancreatic duct was not improved at the time of bone marrow transplantation. The patient has been alive for 3 years since the initial development of AML without relapse of AML or pancreatitis.

\section{Discussion}

We reported the case of a patient with AML who developed acute pancreatitis as an initial symptom. We diagnosed the cause of acute pancreatitis as invasion of AML. As fever with abdominal pain is a relatively atypical symptom for AML, systemic chemotherapy followed by bone marrow transplantation resolved the pancreatitis and leukemia without pancreatic sequelae.

Acute pancreatitis involves inflammation of the pancreas, and may be associated with a systemic inflammatory response that can impair the function of other organs or systems (2). Most cases develop with sudden abdominal pain and severe cases are associated with a high rate of mortality (3). The pathophysiology of acute pancreatitis by imaging is divided into interstitial edematous pancreatitis and necrotic pancreatitis. The etiologies of pancreatitis are alcoholinduced, gall bladder stone-induced and post endoscopic retrograde cholangiopancreatography, but drug-induced and mumps virus-induced pancreatitis have also been reported (4). L-asparaginase-associated pancreatitis is well known to occur in association with treatment in leukemia patients (5). Malignant tumors rarely cause acute pancreatitis; however, pancreatic cancer, intraduct papillary mucinous 


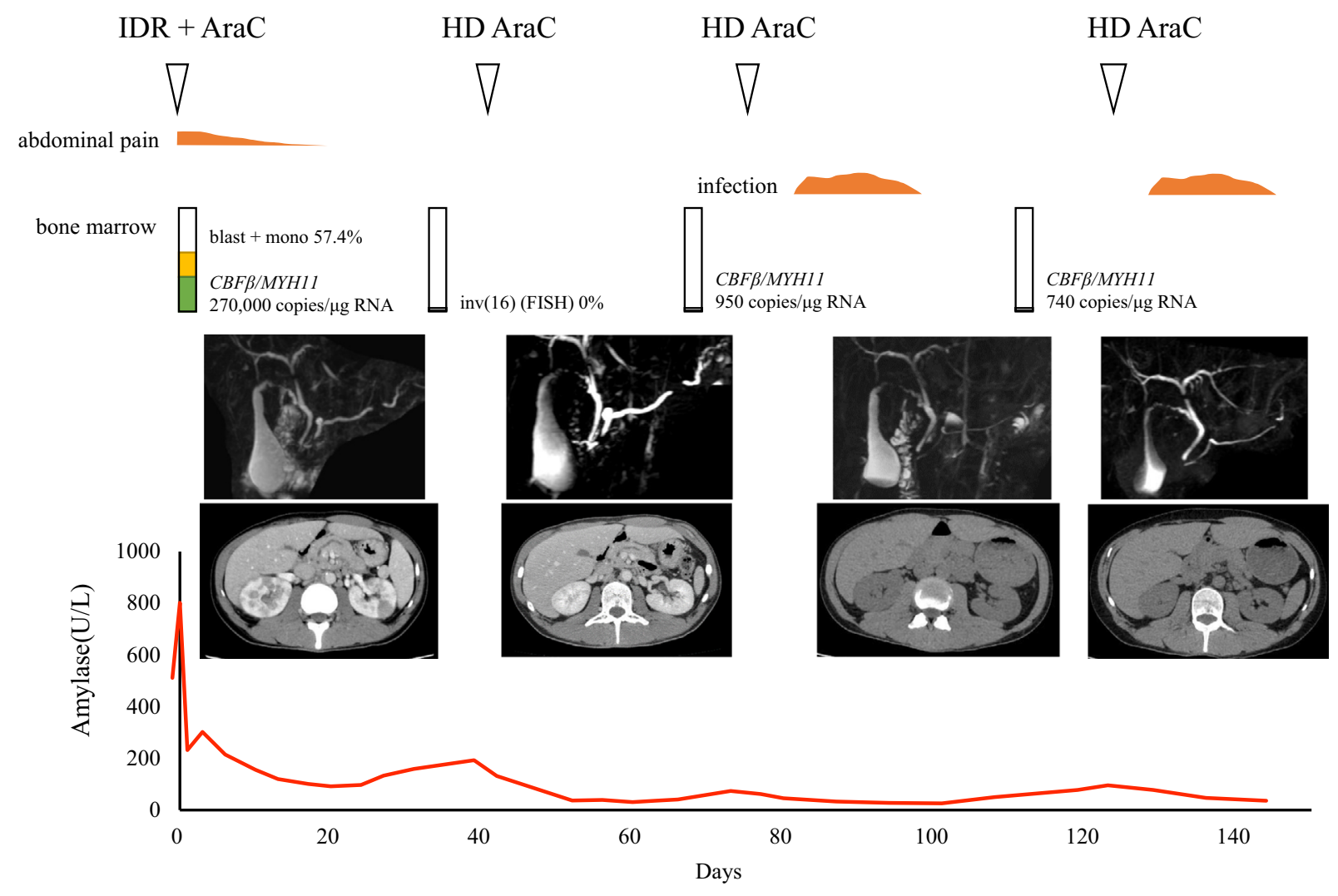

Figure 2. Clinical course. The patient received idarubicin and cytarabine as induction therapy and achieved a hematological remission. Leukemia and pancreatitis both improved after chemotherapy, and the abnormal pancreas and kidney findings disappeared after the first course of consolidation chemotherapy. IDR: idarubicin, AraC: cytarabine, HD AraC: high-dose cytarabine, FISH: fluorescence in situ hybridization, mono: monocyte, RNA: ribonucleic acid

neoplasm, metastatic pancreatic cancer, pancreatic neuroendocrine tumor, biliary cancer and papillary cancer of the duodenal papilla were previously reported to induce acute pancreatitis (6). We diagnosed our patient with acute pancreatitis based on abdominal pain, increased serum amylase and the swelling of the pancreas on CT. Furthermore, a bone marrow examination confirmed AML. As disseminated intravascular coagulation developed on admission, we were unable to perform a biopsy because of the high possibility of pancreatic hemorrhage after the procedure. However, the cause of pancreatitis was suggested to be AML invasion because induction chemotherapy improved both pancreatitis and leukemia.

Eleven cases of acute pancreatitis with leukemia, excluding cases of pancreatitis induced by chemotherapy, have been reported (7-16) (Table). The ages ranged from 11 years to 76 years, and six of the patients were male. The types of leukemia were as follows: adult T-cell leukemia/lymphoma $(n=5)$, acute lymphoblastic leukemia $(n=3)$, and acute myeloid leukemia, acute promyelocytic leukemia and chronic lymphocytic leukemia (CLL; $n=1$ each). Imaging of pancreatitis revealed diffuse swelling in 8 cases, and stenosis or dilatation was noted in the main pancreatic duct. The suspected etiologies of pancreatitis included hypercalcemia, invasion of leukemia cells, and obstruction of the pancreatic duct by leukemia cells. Autoimmune pancreatitis was confirmed in the case of CLL. Needle biopsy was performed in two cases and revealed invasion of leukemia. Systemic chemotherapy was effective for both leukemia and pancreatitis in two of three cases.

One of the characteristics in our case was imaging findings mimicking autoimmune pancreatitis. In 1995, autoimmune pancreatitis was proposed as a subtype of pancreatitis with an autoimmune etiology for which steroid therapy is effective (17). Its imaging findings consist of diffuse swelling of the pancreas and stenosis of the main pancreatic duct $(18,19)$. High serum IgG4 was often described as a feature of autoimmune pancreatitis; however, normal serum IgG4 levels were observed in $24 \%$ of autoimmune pancreatitis cases (20). Our case was atypical as autoimmune pancreatitis because imaging of the main pancreatic duct revealed dilatation rather than stenosis. Furthermore, speckled/ dotted enhancement, a capsule-like rim and duct-penetrating sign, characteristics of autoimmune pancreatitis, were not observed. We concluded that pancreatitis developed due to the invasion of leukemia cells because systemic cytotoxic chemotherapy induced the simultaneous remission of both pancreatitis and leukemia. We hypothesize that anti-tumor immune reactions and/or invasion of leukemia cells indirectly found in the pancreas by imaging modalities were due 
Table. Cases of Acute Pancreatitis at the Onset of Leukemia.

\begin{tabular}{|c|c|c|c|c|c|}
\hline Reference & $\begin{array}{l}\text { Age and } \\
\text { sex }\end{array}$ & $\begin{array}{l}\text { Leukemia } \\
\text { subtype }\end{array}$ & Imaging & Cause of pancreatitis & Treatment \\
\hline 7 & $38 \mathrm{~F}$ & ATLL & $\begin{array}{l}\text { swelling, patchy low density } \\
\text { areas within pancreas }\end{array}$ & hypercalcemia & chemotherapy \\
\hline 7 & $39 \mathrm{M}$ & ATLL & $\begin{array}{c}\text { swelling, macular echo } \\
\text { pattern, smoothly dilated PD }\end{array}$ & hypercalcemia & supportive care \\
\hline 8 & $44 \mathrm{~F}$ & ATLL & $\begin{array}{l}\text { swelling, ascites, fat } \\
\text { stranding }\end{array}$ & hypercalcemia & supportive care \\
\hline 9 & $50 \mathrm{~F}$ & ATLL & $\begin{array}{l}\text { swelling, irregular dilation } \\
\text { of main PD }\end{array}$ & $\begin{array}{c}\text { infiltration } \\
\text { (diagnosed via FNB) }\end{array}$ & chemotherapy \\
\hline 10 & $42 \mathrm{M}$ & $\begin{array}{l}\text { B precursor } \\
\text { ALL }\end{array}$ & fat stranding & $\begin{array}{l}\text { infiltration (presumed } \\
\text { by other lesions) }\end{array}$ & chemotherapy \\
\hline 11 & $76 \mathrm{M}$ & CLL/SLL & $\begin{array}{l}\text { fullness of the pancreas } \\
\text { head, common bile duct } \\
\text { stricture }\end{array}$ & $\begin{array}{l}\text { AIP (resected } \\
\text { specimen) }\end{array}$ & surgery \\
\hline 12 & $34 \mathrm{~F}$ & ATLL & swelling, fat stranding & $\begin{array}{l}\text { infiltration or } \\
\text { hypercalcemia }\end{array}$ & N/A \\
\hline 13 & $30 \mathrm{M}$ & $\begin{array}{l}\text { AML relapse } \\
\text { after U-BMT }\end{array}$ & $\begin{array}{l}\text { swelling, irregular narrowing } \\
\text { of main PD }\end{array}$ & $\begin{array}{c}\text { infiltration } \\
\text { (diagnosed via FNB) }\end{array}$ & supportive care \\
\hline 14 & $11 \mathrm{M}$ & T-ALL & $\begin{array}{l}\text { dilation of PD, duodenal } \\
\text { wall thickening }\end{array}$ & PD obstruction & surgery \\
\hline 15 & $25 \mathrm{~F}$ & T-ALL & swelling, low density areas & infiltration & supportive care \\
\hline 16 & $49 \mathrm{M}$ & APL & N/A & N/A & supportive care \\
\hline $\begin{array}{l}\text { Present } \\
\text { case }\end{array}$ & $33 \mathrm{M}$ & $\begin{array}{l}\text { AML with } \\
\text { inv(16) }\end{array}$ & $\begin{array}{c}\text { swelling (head }>\text { body or tail), } \\
\text { beaded dilation and } \\
\text { obstruction of main PD }\end{array}$ & infiltration & chemotherapy \\
\hline
\end{tabular}

PD: pancreatic duct, N/A: not available, FNB: fine needle biopsy, ATLL: adult T-cell leukemia/lymphoma, CLL/SLL: chronic lymphocytic leukemia/small lymphocytic lymphoma, ALL: acute lymphoblastic leukemia, APL: acute promyelocytic leukemia, AML: acute myeloid leukemia, Ara-C: cytarabine, AIP: autoimmune pancreatitis

to an autoimmune pancreatitis-like diffuse swelling pattern, which is atypical of conventional autoimmune pancreatitis. In the relapse phase of AML, autoimmune pancreatitis-like findings on magnetic resonance imaging have been reported and paraneoplastic autoimmune pancreatitis in metastatic breast cancer patients was also reported recently $(13,21,22)$. However, acute pancreatitis in leukemia is rare and the mechanisms underlying the development of pancreatitis in our patient remain unclear. More clinical cases are needed.

AML with $\operatorname{inv}(16)$ (p13.1q22) is considered a favorable subset of AML; however, our patient relapsed relatively soon after initial therapy and developed extramedullary infiltration of leukemia. Extramedullary leukemia in inv(16)(p13 q22) is relatively frequent, developing at a rate of $19 \%$ in 27 cases, with the most common lesions being cervical lymphadenopathy with or without tonsillar enlargement; this cervico-tonsillar extramedullary involvement is associated with a shorter duration of first remission (23). In another report, the frequency of extramedullary tumors in leukemia with RUNX1-RUNXITI and CBFß-MYHII was $10 \%$, and they were a negative prognostic factors in leukemia with RUNX1-RUNX1T1, but not CBFß-MYH11 (24). C-kit and FLT3 mutations were reported to be negative prognostic factors in AML with inv16(p13.1q22) (24-26). We did not examine these mutations, but they may have played a role in the early relapse in our case. A chromosomal analysis at the diagnosis demonstrated trisomy 22, which was reported to be a favorable factor in AML with inv(16) or $\mathrm{t}(16 ; 16)(26)$; however, how this chromosomal abnormality affected the prognosis is unclear. The association between AML complicated by acute pancreatitis and the prognosis remains unknown. The accumulation of further cases is required.

In conclusion, we described a case of AML that initially developed with acute pancreatitis. We considered the etiology of acute pancreatitis to be the invasion of leukemia cells because systemic cytotoxic chemotherapy ameliorated both leukemia and pancreatitis. Acute pancreatitis is rare as a symptom of leukemia; however, we should consider the possibility of leukemia during the differential diagnosis of acute pancreatitis.

The authors state that they have no Conflict of Interest (COI).

\section{References}

1. Rose-Inman H, Kuehl D. Acute leukemia. Hematol Oncol Clin North Am 31: 1011-1028, 2017.

2. Johnson CD, Besselink MG, Carter R. Acute pancreatitis. BMJ 349: $\mathrm{g} 4859,2014$.

3. Yokoe M, Takada T, Mayumi T, et al. Japanese guidelines for the management of acute pancreatitis: Japanese Guidelines 2015. J Hepatobiliary Pancreat Sci 22: 405-432, 2015.

4. Isaji S, Takada T, Mayumi T, et al. Revised Japanese guidelines for the management of acute pancreatitis 2015: revised concepts and updated points. J Hepatobiliary Pancreat Sci 22: 433-445, 2015. 
5. Wolthers BO, Frandsen TL, Baruchel A, et al. Asparaginaseassociated pancreatitis in childhood acute lymphoblastic leukaemia: an observational Ponte di Legno Toxicity Working Group study. Lancet Oncol 18: 1238-1248, 2017.

6. Balthazar EJ. Pancreatitis associated with pancreatic carcinoma. Preoperative diagnosis: role of $\mathrm{CT}$ imaging in detection and evaluation. Pancreatology 5: 330-344, 2005.

7. Dazai Y, Katoh I, Hara Y, Yoshida R, Kurihara K. Two cases of adult T-cell leukemia associated with acute pancreatitis due to hypercalcemia. Am J Med 90: 251-254, 1991.

8. Ono Y, Kimura T, Nakano I, et al. Acute pancreatitis induced by hypercalcaemia associated with adult T-cell leukaemia: a case report. J Gastroenterol Hepatol 11: 193-195, 1996.

9. Mori A, Kikuchi Y, Motoori S, Watanabe J, Shinozaki M, Eguchi M. Acute pancreatitis induced by diffuse pancreatic invasion of adult T-cell leukemia/lymphoma cells. Dig Dis Sci 48: 1979-1983, 2003.

10. Hanbali A, Kuriakose P, Bansal I, Maeda K. Acute pancreatitis induced by adult precursor B-cell acute lymphoblastic leukemia associated with complex cytogenetics. South Med J 100: 548-549, 2007.

11. Kim T, Grobmyer SR, Dixon LR, Allan RW, Hochwald SN. Autoimmune pancreatitis and concurrent small lymphocytic lymphoma: not just a coincidence? J Gastrointest Surg 12: 1566-1570, 2008.

12. Popescu M, Popov V, Popescu G, et al. Acute pancreatitis: the onset digestive manifestation, in a patient with adult T-cell leukemia/ lymphoma. Rom J Morphol Embryol 53 (Suppl): 847-850, 2012.

13. Ozeki K, Morishita Y, Sakai D, et al. Relapse of acute myeloid leukemia mimicking autoimmune pancreatitis after bone marrow transplantation. Intern Med 53: 247-251, 2014.

14. Kraynik J, Noel JM, Bluefeather SC. Occult T-cell acute lymphoblastic leukemia presenting as obstructive pancreatitis. J Pediatr Gastroenterol Nutr 60: e43-e45, 2015.

15. Yadav YK, Mallya V, Ahluwalia C, Gupta O. Secondary pancreatic involvement by precursor T-cell acute lymphoblastic leukemia presenting as acute pancreatitis. Indian J Cancer 52: 465-467, 2015 .

16. Abdullah AS, Adel AM, Hussein RM, et al. Hypercalcemia and acute pancreatitis in a male patient with acute promyelocytic leukemia and pulmonary tuberculosis. Acta Bio-medica: Atenei Parmensis 89 (3-s): 23-27, 2018.

17. Yoshida K, Toki F, Takeuchi T, Watanabe S, Shiratori K, Hayashi
N. Chronic pancreatitis caused by an autoimmune abnormality. Proposal of the concept of autoimmune pancreatitis. Dig Dis Sci 40: 1561-1568, 1995.

18. Kloppel G, Detlefsen S, Chari ST, Longnecker DS, Zamboni G. Autoimmune pancreatitis: the clinicopathological characteristics of the subtype with granulocytic epithelial lesions. J Gastroenterol 45: 787-793, 2010.

19. Zhang L, Chari S, Smyrk TC, et al. Autoimmune pancreatitis (AIP) type 1 and type 2: an international consensus study on histopathologic diagnostic criteria. Pancreas 40: 1172-1179, 2011.

20. Ghazale A, Chari ST, Smyrk TC, et al. Value of serum IgG4 in the diagnosis of autoimmune pancreatitis and in distinguishing it from pancreatic cancer. Am J Gastroenterol 102: 1646-1653, 2007.

21. Tokunaga $\mathrm{K}$, Yamamura $\mathrm{A}$, Ueno $\mathrm{S}$, et al. Isolated pancreatic myeloid sarcoma associated with $\mathrm{t}(8 ; 21) /$ RUNX1-RUNX1T1 rearrangement. Intern Med 57: 563-568, 2018.

22. Lekakis L, Tryfonopoulos D, Fakinos G, et al. A case of paraneoplastic autoimmune pancreatitis: mini-review of paraneoplastic syndromes in breast cancer. Anticancer Res 32: 3311-3314, 2012.

23. Billström R, Ahlgren T, Békássy AN, et al. Acute myeloid leukemia with inv(16)(p13q22): involvement of cervical lymph nodes and tonsils is common and may be a negative prognostic sign. Am J Hematol 71: 15-19, 2002.

24. Ishikawa Y, Kawashima N, Atsuta Y, et al. Prospective evaluation of prognostic impact of KIT mutations on acute myeloid leukemia with RUNX1-RUNX1T1 and CBFB-MYH11. Blood Adv 4: 66$75,2020$.

25. Ayatollahi H, Shajiei A, Sadeghian MH, et al. Prognostic importance of $c$-kit mutations in core binding factor acute myeloid leukemia: a systematic review. Hematol Oncol Stem Cell Ther 10: 17, 2017.

26. Paschka P, Du J, Schlenk RF, et al. Secondary genetic lesions in acute myeloid leukemia with $\operatorname{inv}(16)$ or $t(16 ; 16)$ : a study of the German-Austrian AML Study Group (AMLSG). Blood 121: 170177, 2013.

The Internal Medicine is an Open Access journal distributed under the Creative Commons Attribution-NonCommercial-NoDerivatives 4.0 International License. To view the details of this license, please visit (https://creativecommons.org/licenses/ by-nc-nd/4.0/).

(C) 2021 The Japanese Society of Internal Medicine Intern Med 60: 1753-1757, 2021 